\section{International Journal of Research in Social Science and Humanities (IJRSS)}

DOI: doi.org/10.47505/IJRSS.2020.9155
E-ISSN : 2582-6220

Volume 1, Issue 4

Sep-Oct - 2020

\title{
Engagement of Out of School Youth in Decision Making During Showcasing of Success Stories by Young Agripreneurs and Its Effect on Implementation of Agricultural Programmes
}

\author{
Martha K. Nyang'au ${ }^{1}$, Albert M. Getabu ${ }^{2}$, Samson N. Maobe ${ }^{2}$, Evans A. Basweti ${ }^{2}$ \\ and Washington A. Ochola ${ }^{1}$ \\ ${ }^{l}$ Department of Agricultural Education and Extension \\ ${ }^{2}$ Faculty of Agriculture and Natural Resources Management, \\ Kisii University, P.O Box 408-40200, Kisii, Kenya.
}

\begin{abstract}
Participation of out of school youth in decision making on showcasing success stories by young agripreneurs would act as motivation for them to increase implementation of agricultural programmes for self reliance. However, there is problem of low participation of out of school youth in decision making on showcasing success by young agripreneurs. Out of school youths who have completed secondary school agriculture are scantly exposed in agripreneurship. It is expected that the gap in knowledge and skills would be filled by the youth participating in showcasing success events by young agripreneurs. This research was conducted to establish the influence of participation of out of school youth in decision-making on showcasing success stories by young agripreneurs on implementation of agricultural programmes. The investigation was conducted in three categories of secondary schools offering agriculture subject, spread in five agro-ecological zones typical of Kenyan farm types, and found in Kisii and Nyamira counties region. Cross-sectional survey design was used. Out of school youth are those who studied agriculture subject and are registered with youth groups within their localities engaged in agricultural activities for creation of livelihoods. Stratified, purposive, and simple random sampling procedures were used to select a sample size of 160 out of school youth. Data was collected using questionnaires, analyzed by descriptive and inferential statistics at probability level of 0.05 using SPSS version 21. Results show that gender of out of school youth does not make a significant difference in the level of participation in decision making on showcasing events by young agripreneurs. Youth out of school are in concurrence that strategies 5, 4, 3 and 6 are more significantly very important than the rest in increasing their participation in decision making during showcasing success stories by young agripreneurs. Strategy 5 is identified as outstanding out of the four and advocates for the formation of agribusiness clubs at community level where successful agripreneurs can mentor the out of school youth, share ideas, experiences and showcase their successes. There is a positive significant linear correlation between level of participation in decision making during showcasing of success stories by young agripreneurs and the level of implementation of agricultural programmes by youth out of school $(R=0.438762, p=0.00)$. These findings will be useful in addressing issues of out of school youth on participation in decision making during showcasing success stories by young agripreneurs to prompt them implement agricultural programmes for independence.
\end{abstract}

Key words: Out-Of-School Youth, Decision-Making, Showcasing Agripreneurs, Strategies.

\subsection{INTRODUCTION}

The introduction of teaching of agriculture in schools in 1965 was based on participatory curriculum implementation that brought on board stakeholders such as the Government and its development partners, communities, families, and the informal sector such as faith organizations (Konyango, 2015). Government supported teaching of agriculture in schools as a way of initiating young people into farming occupation and creation of jobs in rural areas thereby solving the unemployment problem. Donors such as the World Bank considered the programme as means to stimulate growth of country's agricultural sector and the economy by creating a critical mass of rural inhabitants knowledgeable in agriculture. Also, by experiential learning plots put up by agriculture students in rural areas, serving agricultural extension purpose by the demonstrating improved production practices, new technologies and 
agripreneurship thereby acting as agents of change. Government supported teaching of the subject by training agriculture teachers, and providing facilities, equipment and developing the school farm as out of classroom laboratory for learning, and to impart vocational skills to the youth for self reliance out of school (Konyango, 2015). However over time, emphasis of school agriculture shifted from aspirations of the participatory curriculum implementation developers as a means to impart skills for self reliance to purely academic objective in pursuit of high examination grades that would secure jobs and reward more in the job market as compared to skills gained. Moreover, school farm has been diverted to commercial use outside the management of the agriculture teacher. Provision of facilities and equipment required for teaching agriculture got discontinued and those given earlier are run down, aged and non-existent. Some of the agriculture teachers might have shifted to concentrate in teaching biology which has little demand in facilities and equipment whose request from school management becomes a source of conflict. Teaching of agriculture has become chalk-talk devoid of any practical. Therefore, youth that have completed school agriculture programme are inadequate in vocational skills necessary for implementation of agricultural programmes to create livelihoods. Youth are expected to fill up the gap in knowledge and acquisition of more and specialized skills by participation in the implementation of agricultural extension programmes. However, there is low participation of out of school youth in agricultural extension programmes such as showcasing success stories by young agripreneurs. The low participation has been attributed to limited engagement of out of school youth in decision making on agricultural programmes. Consequently, agricultural programmes meant to benefit young people have been implemented with little if any youth voice, as result of which they have been unsuccessful in meeting their objective of enabling youth become self reliant. This is despite the idea of "student voice," or youth role in decision making and change efforts, having emerged as a potential strategy for improving youth development and outcomes (United Nations (UN), 2003). Wierenga, Wood, Trenbath, Kelly \& Vidakovic (2003) note that letting young people share success stories entails meaningful engagement and recognizing them as co-creators of their communities. It involves youth participation in making decisions, being heard and thus also having the skills to see the task through and do it well. It also requires connectedness whereby youth work with others and become part of something bigger.

Borden, Perkins, Villarruel, Carleton-Hug, Stone and Keith (2006) state that, time spent in youth programs is the most consistent predictor of youth thriving. Compared to family and community factors, participation in youth programs contributes to enhanced self-esteem, increased school performance and aspirations to attend college, the ability to overcome adversity, willingness to engage in efforts to help others, leadership skills, efforts to maintain good physical health, and involvement in political and social activities in young adulthood. Despite these robust findings, much less is known about the factors that influence young people's decision to participate in youth programs or the barriers that influence their lack of participation (Borden, Perkins, Villarruel, Carleton-Hug, Stone and Keith, 2006).

\subsection{Statement of problem}

Participation of youth in showcasing success stories in agripreneurship would act as stimulus to increase implementation of agricultural programmes to achieve self reliance in young people in rural areas. However, there is a problem of low participation of youth in showcasing successes in agripreneurship leading to insufficient incentive for young people to implement agricultural programmes. The low participation of youth has been attributed to their inadequate engagement in decision making during showcasing of success stories in agripreneurship. Kenya institute of education (KIE) curriculum on school agriculture programme is inadequate in the aspect of agripreneurship despite its importance as source of inspiration for youth to implement agricultural programmes for independence. It is for these reasons that the present research was carried out to investigate out of school youth participation in decision making during showcasing successes by young agripreneurs.

\subsection{Objective of the study}

To determine the influence of participation of out of school youth in decision-making during showcasing success stories by young agripreneurs to prompt them implement agricultural programmes for self reliance, and evaluate strategies proposed to enhance their engagement for success.

\subsection{Hypothesis}

The following hypothesis was tested at probability level of 0.05 .

$\mathrm{Ho}_{1:}$ There is non-significant difference in the participation of out of school youth in decision making during showcasing success stories by young agripreneurs to encourage them implement agricultural programmes.

\subsection{METHODOLOGY}

\subsection{Study area}

The study was carried out in Kisii and Nyamira counties region, southwest Kenya in 2019. Jaetzold and Schmidt (1982) characterized the region into five agro-ecological zones (AEZs). The characterization is done basing on production potential of the 
area, cropping, livestock systems and taking into account climatic factors of rainfall and temperature found in different parts. In this study, the agro-ecological zones were adopted as different farm type zones and used as unique sampling locations. They were used to obtain diverse youth population segments with varied exposures, opportunities and experiences in agriculture, and participation in decision making during showcasing successes in agripreneurship and implementation of agricultural programmes. The farm types indicated by the agro-ecological zones are typical of similar ones found in other parts of Kenya and therefore representative of major ones available to the youth, and are as follows: 1) Tea-dairy zone, 2) Tea -coffee zone, 3) Maizepyrethrum zone, 4) Coffee-banana zone and, 5) Marginal sugarcane zone.

\subsection{Study Population}

The out of school youth were purposefully sampled from members of registered youth groups spread across the five farm type zones of the two counties. The groups are engaged in agricultural activities for creation of livelihoods for its membership. Specifically youth who had studied school agriculture and therefore presumed to have acquired skills for independence were selected for the study. These youth lack formal employment and find themselves in rural areas where more than $75 \%$ of the population is engaged in agriculture for livelihoods. Despite having completed school, such youth attend agricultural shows, field learning trips, farm visits and other events meant to showcase success stories in agripreneurship. Such exhibitions are usually by adult farmers and are taken to serve the purpose of imparting skills and knowledge that would be helpful to the youth for independence. In some cases the youth may attend vocational training Centers to acquire more and specialized skills for self reliance. The situation is typical for young people in most African countries. The out of school youth have therefore fallen back to the skills gained in school agriculture programme as expected for independence in the absence of alternative jobs and as envisaged in participatory curriculum implementation.

\subsection{Research Design}

The research adopted ex-post facto research design and a cross-sectional survey design to study the influence of participation of out of school youth in decision making during showcasing success stories by young people to inspire others implement agricultural programmes for self reliance. The design was adopted because the researcher without applying any treatment studied the influence of participation of out of school youth in decision making on showcasing success stories by young agripreneurs which is a naturally occurring phenomenon without any manipulation (Cohen, Manion, \& Morrison, 2007; and Kothari, 2004). The study used questionnaires that were administered face to face so cross-sectional survey design was considered most convenient approach.

\subsection{Sample Size and Sampling Procedure}

Krejcie \& Morgan (1993), Kathuri \& Pals (1970) summarizes the sample sizes that could be used for research and corresponding target populations. There are 280 out of school youth, purposefully identified in the five farm types as having studied agriculture in secondary school up to form four. This study adopted a sample size of 160 out of 280 out of school youths. They are registered with 75 youth groups involved in agricultural activities for creation of livelihoods, and spread in the five farm type zones. Sampling from the farm types was in accordance with proportionate distribution in the farm type zones, and is as follows: teadairy zone - 29 youths, maize-pyrethrum - 9 youths, tea- coffee - 32 youths, coffee-banana - 32 youths, marginal sugarcane zone -58 youths. The samples make a total of 160 respondents.

\subsection{Instrumentation and data collection procedures}

Data was collected using questionnaires because the respondents involved were literate and, therefore could read the questions and respond appropriately by filling. Daniel (2004) indicates that with questionnaires the participants can fill at their own convenience, and that it allows some time for the respondents to familiarize with the questions and think about the answers. The questionnaires that were used are closed type and had two likert rating scales; one coded from 1 to 10 , where: $1-4=$ low; $5-7=$ average and $8-10=$ high levels of participation. This was used to measure the level of participation of youth in decision making and level of implementation of showcasing success stories by young agripreneurs. The other scale was coded, 1 to 5, where: 1=Not Important; 2=Least important; 3=Important; 4=Very Important, 5=Extremely Important. It was used to rate the six strategies proposed to increase participation of youth in decision making during showcasing success stories by young agripreneurs to trigger off implementation of agricultural programmes.

\subsection{Data Analysis}

The following qualitative and quantitative statistical tools were applied in data analysis: percentages, two tailed t-test, analysis of variance F-test, Tukey post hoc test, Spearman rank correlation two tailed test and linear correlation coefficient. The two tailed ttest was used to determine the differences in gender of out of school youth in decision-making during showcasing success stories by young agripreneurs. The analysis of variance (ANOVA) F-test was used to establish if there were significant differences 
among out of school youth in decision-making on showcasing success stories by young people as a result of gender. Tukey post hoc test was applied in mean separation where there were significant differences. Spearman rank correlation coefficient two tailed test was employed to determine the relationship between the level of participation in decision-making on showcasing success stories by young agripreneurs and the level of implementation of agricultural programmes. Linear correlation coefficient was used to establish the influence of participation in decision making during showcasing success stories by young agripreneurs on implementation agricultural programmes by out of school youth. Tables and scatter plot graph were used to present the results.

\subsection{RESULTS}

\subsection{Level of exposure of out of school youth by gender on showcasing success stories by young agripreneurs}

A bout $35 \%$ of out of school youth comprising males (15\%) and females (20\%) are exposed to showcasing success stories by young agriprenures at high participation level 8 (Table 1). The t-test result in Table 2 indicates non-significant difference between male $(\mathrm{M}=5.697368, \mathrm{SD}=8.107193)$ and female out of school youth $(\mathrm{M}=6.392857, \mathrm{SD}=5.807659) ; \mathrm{t}(158)=1.975092, \mathrm{p}$ $=0.096397$ ) on showcasing successes by young agripreneurs (Table 2). Therefore, gender of out of school youth does not influence the level of exposure of out of school youth to showcasing success stories by young agri-preneurs.

\subsection{Level of consultation of out of school youth by gender on showcasing success stories of young entrepreneurs}

There were $36 \%$ of out of school youth made up of males (16\%) and females (20\%) who indicated that they are consulted at high participation level 8 in showcasing success stories by young agripreneurs (Table 3). The t-test result in Table 4 reveal that there is a non-significant difference between out of school male $(\mathrm{M}=5.631579, \mathrm{SD}=7.542456)$ and female out of school youth $(\mathrm{M}=$ $6.25, \mathrm{SD}=6.671687) ; \mathrm{t}(158)=1.975092, \mathrm{p}=0.144208)$ on the level of consultation during showcasing success stories by young agripreneurs.

Table 1: Cross tabulation on level of exposure of out of school youth by gender to showcasing success stories by young agripreneurs

\begin{tabular}{|c|c|c|c|c|c|c|c|c|c|c|c|}
\hline \multirow[t]{2}{*}{ Gender } & \multicolumn{10}{|c|}{$\begin{array}{l}\text { Level of exposure to showcasing success stories by youth } \\
\text { Agripreneurs }\end{array}$} & \multirow[t]{2}{*}{ Total } \\
\hline & 1.00 & 2.00 & 3.00 & 4.00 & 5.00 & 6.00 & 7.00 & 8.00 & 9.00 & 10.00 & \\
\hline Male & 10 & 4 & 4 & 8 & 9 & 8 & 5 & 15 & 7 & 6 & 76 \\
\hline Female & 4 & 1 & 6 & 8 & 12 & 8 & 10 & 20 & 7 & 8 & 84 \\
\hline Total & 14 & 5 & 10 & 16 & 21 & 16 & 15 & 35 & 14 & 14 & 160 \\
\hline
\end{tabular}

Table 2: T- test result on the differences of out of school youth by gender on level of exposure to showcasing success stories by young agripreneurs

\begin{tabular}{lllllll}
\hline Respondents & $\mathrm{n}$ & $\begin{array}{l}\text { Participation } \\
\text { mean score }\end{array}$ & (Std Dev.) & df & t-value & P - value \\
& 76 & 5.697368 & 8.107193 & 158 & 1.975092 & 0.096397 \\
Male & 84 & 6.392857 & 5.807659 & & & \\
\hline
\end{tabular}

Table 3: Cross tabulation on level of consultation of out of school youth by gender on showcasing success stories by young agripreneurs

\begin{tabular}{lccccccccccccc}
\hline Gender & \multicolumn{1}{c}{ Level of Consultation on Success Stories for Exposure } & \multicolumn{4}{c}{ Total } \\
& 1.00 & 2.00 & 3.00 & 4.00 & 5.00 & 6.00 & 7.00 & 8.00 & 9.00 & 10.00 \\
\hline Male & 11 & 0 & 10 & 6 & 7 & 4 & 12 & 16 & 8 & 2 & 76 \\
& & & & & & & & & & & \\
Female & 7 & 2 & 4 & 6 & 16 & 4 & 8 & 20 & 12 & 5 & 84 \\
Total & 18 & 2 & 14 & 12 & 23 & 8 & 20 & 36 & 20 & 7 & 160 \\
\hline
\end{tabular}


Table 4: T-test result on the differences of out of school youth by gender in level of consultation on showcasing success stories by young agripreneurs

\begin{tabular}{lllllll}
\hline Respondents & $\mathrm{n}$ & $\begin{array}{l}\text { Participation } \\
\text { mean score }\end{array}$ & (Std Dev.) & $\mathrm{df}$ & $\mathrm{t}$-value & $\mathrm{P}$ - value \\
\hline Male & 76 & 5.631579 & 7.542456 & 158 & 1.975092 & 0.144208 \\
Female & 84 & 6.25 & 6.671687 & & & \\
\hline
\end{tabular}

\subsection{Rating of strategies proposed to increase participation of youth in decision making during showcasing success stories by young agripreneurs}

The analysis of variance F-test results in Table 5 indicates that there are significant differences $(\mathrm{F}=23.62118, \mathrm{p}$ value $<.01)$ in the ratings of the strategies proposed for increasing participation of out of school youth in decision making during showcasing of success stories by young agripreneurs. Tukey post hoc test results in Table 6 shows that strategy 5 has significantly the highest mean rating $(\mathrm{M}=4.231)$ compared to the rest. Strategy 5 advocates for the formation of agribusiness clubs at community level where successful agripreneurs can mentor out of school youth, share ideas, experiences and showcase their success stories. Strategies 4, 3 and 6 are ranked similar but with significantly higher rating than strategies 2 and 1 (Table 6). From the results, it is notable that out of school youth are in concurrence that strategies5, 4, 3 and 6 are more significantly very important than 1 and 2 . The strategy 5 which is outstanding on showcasing success stories by youth agripreneurs is the subject of this study.

3.4 Relationship between level of participation in decision making on showcasing success stories by young agripreneurs and level of implementation of agricultural programmes by out of school youth

The regression correlation results (Tables 7 and 8$)$ indicate that there is a positive significant correlation $(\mathrm{R}=0.438762, \mathrm{p}<.0 .01)$ between the level of participation in decision making on showcasing success stories by young agripreneurs and level of implementation of agricultural programmes by out of school youth. Further analysis by linear correlation coefficient (Figure 1) shows that participation in decision making on showcasing success stories by young agripreneurs accounts for $43.8 \%\left(\mathrm{R}^{2}=0.438\right)$ increase in level of implementation of agricultural programmes. The remaining $56.2 \%$ of the variation would be as a result of other factors.

Table 5: Analysis of variane (ANOVA) F-test results on the differences in rating of strategies proposed to increase out of school youth's participation in decision making on showcasing success stories by young agripreneurs

\begin{tabular}{lllllll}
\hline Source of Variation & $S S$ & $d f$ & $M S$ & $F$ & P-value & F crit \\
Between Groups & 137.0083 & 5 & 27.40165 & 23.62118 & 0.00 & 2.223495 \\
\hline Within Groups & 1105.524 & 953 & 1.160046 & & & \\
Total & 1242.532 & 958 & & & \\
\hline
\end{tabular}

Table 6: Tukey post hoc test results on the differences in rating of strategies proposed by out of school youth for increasing their participation in decision making on showcasing success stories by young agripreneurs

\begin{tabular}{|l|l|l|l|l|l|}
\hline No & \multicolumn{1}{|c|}{ Strategies proposed } & N & \multicolumn{1}{|c|}{$\begin{array}{l}\text { Subset for alpha } \\
=0.05\end{array}$} \\
\cline { 2 - 6 } 1 & $\begin{array}{l}\text { Re-branding of agriculture with trendy names that appeal to youth will } \\
\text { change their poor perception of the sector and embrace agriculture }\end{array}$ & 160 & 3.206 & 2 & 3 \\
\hline 2 & $\begin{array}{l}\text { Successful youth agri-preneurs to conduct campaigns in rural areas to } \\
\text { demystify the notion that agriculture is for the old and uneducated people } \\
\text { in society }\end{array}$ & $\begin{array}{l}\text { The media to showcase communities that guard against ridicule of youth } \\
\text { in agriculture and protect their agribusiness activities from being } \\
\text { vandalized }\end{array}$ & 3.381 & & 3.888 \\
\hline
\end{tabular}


International Journal of Research in Social Science and Humanities (IJRSS), Vol .1(4), Sep-Oct- 2020

\begin{tabular}{|l|l|l|l|l|}
\hline 3 & $\begin{array}{l}\text { Public education by young agri-preneurs to sensitize schools on proper } \\
\text { usage of the school farm to a void portraying agriculture career as } \\
\text { punishment }\end{array}$ & 160 & 3.913 & 3.913 \\
\hline 4 & $\begin{array}{l}\text { Public-private award scheme that will recognize and reward successful } \\
\text { youth agri-preneurs and thus motivate those interested in agriculture }\end{array}$ & 160 & 4.15 & 4.15 \\
\hline 5 & $\begin{array}{l}\text { Forming agribusiness clubs at community level where successful agri- } \\
\text { preneurs can mentor out of school youth, share ideas, experiences and } \\
\text { showcase their success }\end{array}$ & 160 & & 4.231 \\
\hline & Sig. & & .694 & .248 \\
\hline
\end{tabular}

Table 7: Regression results on level of participation in decision making during showcasing success stories by young agripreneurs and level of implementing agricultural programmes by out of school youth.

\begin{tabular}{ll}
\hline Regression & \\
\hline Multiple R & 0.662391 \\
R Square & 0.438762 \\
Adjusted R Square & 0.43521 \\
Standard Error & 1.721644 \\
Observations & 160 \\
\hline
\end{tabular}

Table 8: Correlation coefficient results on level of participation in decision making during showcasing success stories by young agripreneurs and level of implementation of agricultural programmes by out of school youth.

\begin{tabular}{lllllllll}
\hline & & Standardd & & P- & & & Lower & Upper \\
& Coefficients & Error & t Stat. & value & Lower 95\% & Upper 95\% & $95.0 \%$ & $95.0 \%$ \\
\hline $\begin{array}{l}\text { Intercept } \\
\text { X }\end{array}$ & 3.285972 & 0.341651 & 9.617918 & 0.00 & 2.61118 & 3.960764 & 2.61118 & 3.960764 \\
Variable 1 & 0.574479 & 0.05169 & 11.11399 & 0.00 & 0.472387 & 0.676571 & 0.472387 & 0.676571 \\
\hline
\end{tabular}

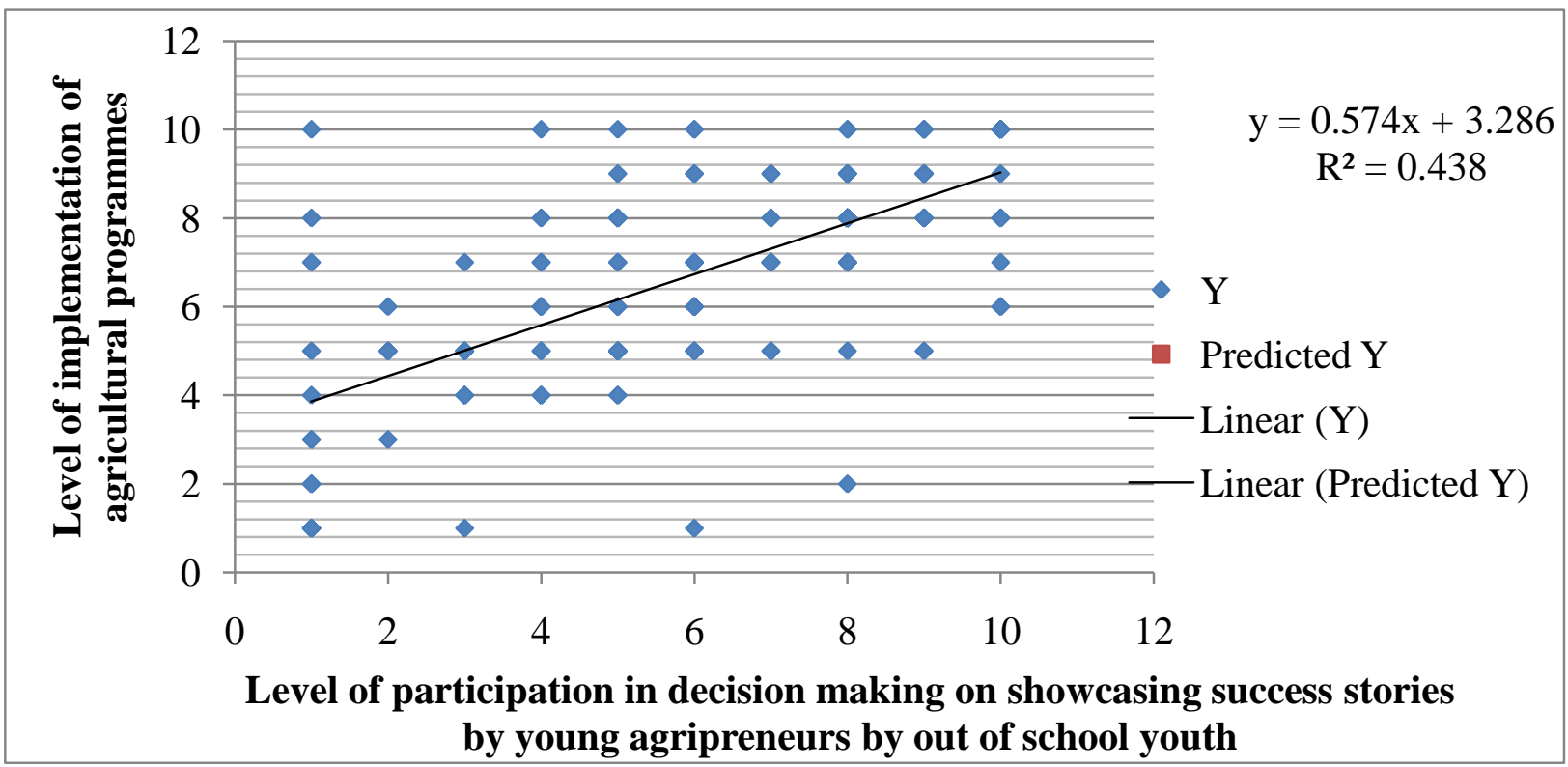

Figure 1: Scatter plot on level of participation in decision making on Showcasing success stories by young agripreneurs and level of implementation of agricultural programmes by out of school youth 


\section{0 DISCUSSION}

4.1 Influence of gender of out of school youth on level of participation in decision making during showcasing success stories by young agripreneurs

The gender of out of school youth does not influence the level of participation in decision making on showcasing success stories by young agripreneurs (Tables 1 and 2). The out of school youth who participated in the study are registered with youth groups involved in promoting agriculture for self reliance amongst its membership. The findings suggest that neither male nor female gender is discriminated on participation in decision making during showcasing success stories by young agripreneurs. The Ministry of agriculture, livestock and fisheries development, Department of agricultural and livestock extension reaches out to young people in rural areas through youth groups. Therefore, the groups are involved in agricultural extension by the Ministry in different forms. It may entail invitation of role models in agribusiness to come and share their success stories with the group members. When such happens the group members are not discriminated on account of gender. Therefore, gender is unlikely to influence implementation of agricultural programmes on account of exposure to success stories by young agripreneurs amongst out of school youth.

\subsection{Influence of gender of out of school youth on level of participation in decision making on consultation in showcasing} success stories by young entrepreneurs

There is a non-significant difference between out of school male and female youth on level of participation in decision making on consultation during showcasing success stories by young agri-preneurs (Tables 3 and 4). Therefore, male and female out of school youth are consulted to similar level on showcasing successes by young agripreneurs. The out of school youth who participated in the study are registered in youth groups that are actively engaged in agricultural activities for creation of livelihoods. The groups are the avenues through which the Ministry of agriculture, livestock and fisheries development reaches out to young people in the implementation of agricultural extension programmes. These programmes include showcasing success stories by young agripreneurs in agricultural shows, Trade fairs, Field educational trips and exhibitions. The Ministry has mainstreamed youth and gender in its operations, therefore discrimination on account of those factors is unexpected.

\subsection{Rating of strategies proposed to increase participation of out of school youth in decision making during showcasing success stories by young agripreneurs}

The out of school youth are in concurrence that strategies 5, 6, 4 and 3 are more significantly very important than the rest (Tables 5 and 6). Strategies 4, 3 and 6 have similar but considerably higher rating than 2 and 1 (Tables 5 and 6). The strategy 5 advocates for formation of agribusiness clubs at community level where successful agripreneurs can mentor out of school youth, share ideas, experiences and showcase their success and it the subject of this study.

The high rating of four out of the five strategies proposed indicates the need to put those schemes in place to enhance youth participation. As noted by the United Nations (UN), 2003, real empowerment is achieved when young people are able to identify those issues of primary concern to them and to develop strategies, activities, networks, organizations or campaigns through which to pursue their objectives.

4.4 Relationship between level of participation in decision making during showcasing success stories by young agripreneurs and level of implementation of agricultural programmes by out of school youth

There is a positive significant linear correlation $(\mathrm{R}=0.438762, \mathrm{p}=0.00)$ between the level of participation in decision making during showcasing of success stories by young agripreneurs and the level of implementation of agricultural programmes by out of school youth (Tables 7 and 8). The result implies that an increase in the level of showcasing of the success stories by young agripreneurs would lead to rise in the level of implementation of agricultural programmes by out of school youth (Figure 1). The observation corroborates that by Buragohain, Bordoloi, Lego, Hussian \& Saikia (2018) who noted that the level of participation in the management of agricultural activities of rural youth was increased with enhanced level of exposure to training and media.

\subsection{CONCLUSIONS}

1) Gender of out of school youth does not make a significant difference in level of exposure and consultation on showcasing success stories by young agripreneurs

2) Youth out of school are in concurrence that strategies 5, 4, 3 and 6 are more significantly very important than the rest, with strategy 5 additionally outstanding in its impact on increasing out of school youth participation in decision making on showcasing success stories by young agripreneurs..

3) There is a positive significant linear correlation between level of participation in decision making during showcasing of success stories by young agripreneurs and the level of implementation of agricultural programmes by out of school youth $(\mathrm{R}=$ $0.438762, \mathrm{p}=0.00)$. 


\subsection{RECOMMENDATIONS}

These findings will be useful in addressing issues of out of school on participation in decision making on showcasing success stories of young agripreneurs to prompt them implement agricultural programmes for self reliance.

\section{ACKNOWLEDGEMENTS}

This article is extract of the objective five of $\mathrm{PhD}$ thesis of the first author. We are grateful to the Vice Chancellor, Kisii University for providing a study leave to the main author. Also thankful to the Department of Agricultural Education and Extension, and Dean, Faculty of Agricultural and Natural Resources Management for availing facilities that enabled this research work to be carried out.

\section{REFERENCES}

Abdullah, A. A., \& Terengganu, K. (2013). Factors That Influence the Interest of Youths in Agricultural Entrepreneurship. 4(3), 288-302.

Borden, L. M, Perkins, D. F, Villarruel, F. A, Carleton-Hug, A, Stone, M. R. and Keith, J. G. 2006. Challenges and opportunities to Lotino Youth Development: Increasing Meaningful Participation in Youth Development Programs. Hispanic Journal of Behavioral Sciences, Vol., 28, No., 2, May 2006, pp. 187-207. http://hjb.sagepub.com hosted at http://online.sagepub.com

Buragohain, M., Bordoloi, N., Lego, I., Hussian, H. M., \& Saikia, D. (2018). A Study on Relationship between Extent of Participation in Decision Making Activities, with Socio-Economic and Psychological Characteristics of Rural Youths towards Farming in Jorhat District of Assam. International Journal of Agriculture Sciences(IJAS), 10(3), 5115. https://doi.org/10.9735/0975-3710.10.3.5115-5117

Cheteni, P. (2018). econstor. September 2016. https://doi.org/10.1080/09709274.2016.11907025

Lohento, K., \& Mayenga, D. (2015). Youth in Agribusiness within an African Agricultural Transformation Agenda. An Action Plan for African Agricultural Transformation

Muthomi, E. (2017). Challenges and Opportunities for Youth Engaged in Agribusiness in Kenya.

United Nations (UN), 2003. World Youth Report, Chapter 10, Youth participation in decision making. The World Programme of action for youth to the year 2000 and beyong, United Nations, pp. 271-288. 